\title{
Factors influencing the job satisfaction of nurses working in obstetric units in public hospitals in Kenya
}

\author{
Keziah Wakonyo Kahiga* \\ Daystar University, Nairobi city, Kenya
}

Received: July 31, 2017

DOI: $10.5430 /$ jnep.v8n2p132
Accepted: September 27, 2017 Online Published: October 30, 2017

URL: https://doi.org/10.5430/jnep.v8n2p132

\begin{abstract}
Introduction: The literature demonstrates that little research has been conducted to explore job satisfaction among nurses working in obstetric units in Kenya. The perception of job satisfaction by nurses is influenced by the environment in which they work.

Methods: A cross-sectional survey design was used to carry out the study. The study tools included the work quality index (WQI) and the demographic data questionnaires. Convenience sampling method was. Data were analyzed using the SPSS version 20. The items in the WQI were organized into six subscales and Cronbach's alpha was calculated to obtain the reliability coefficient of each subscale. An independent $t$-test was used to compare the subscales scores for the male and female participants. ANOVA was conducted to compare the level of satisfaction with the six subscales and the participants' characteristics. Pearson's product-moment correlation coefficient was calculated to assess if there was any relationships, the magnitude and the direction of the relationship between the six subscales.

Results: Nurses are most satisfied with the perception that the work associated with their position provides them with the opportunity to be of service to others and least satisfied with receiving enough time to complete indirect patient care tasks. There are no significant differences in the overall level of satisfaction between males and females though males are more satisfied with autonomy of practice and professional role enactment. The six subscales strongly and positively correlate with one another.

Conclusions: Nurses working in the obstetric units are relatively dissatisfied with most of the aspects of the work environment. The more educated nurses are less satisfied than less educated nurses. Since all aspects of job satisfaction are interrelated, emphasis should be put on each of them so as to create a satisfying work environment for nurses working in obstetric units.
\end{abstract}

Key Words: Midwife, Nurse midwife, Nurses' job satisfaction, Magnet hospitals, Obstetrics

\section{INTRODUCTION}

Nurses' job satisfaction has become a critical issue because it has great influence on health care provision and patient outcomes. $^{[1]}$ This is particularly so in the obstetric units since nurses in such units have special tasks in that they often deal with two lives. The conditions in the health care institutions are a major contribution to how nurses perceive their work, their job satisfaction, and whether they desire to leave their institutions or nursing altogether ${ }^{[2]}$ More often than not, nurses generally have not been involved in determining and designing a work environment that could improve the perception of satisfaction with their job.

Nursing as a profession has undergone many changes with numerous innovations and this has put more demand on the nurse-midwives and nurses working in other departments. Consumers of health care are also more knowledgeable and

*Correspondence: Keziah Wakonyo Kahiga; Email: kwnjuguna@gmail.com; Address: Daystar University, Nairobi city, Kenya. 
more sensitivity is required when dealing with them. This means that the factors that satisfied nurses decades ago do not necessarily satisfy today's nurse. It is therefore imperative to involve the nurses and have them identify the factors in the institutions where they work and that they perceive to create job satisfaction.

Good working conditions that supports work effectiveness create job satisfaction and dedication and potentially result in fewer turnovers and more nurses' retention. The perennial shortage of nurses can be attributed to poor and inefficient working conditions which is a worldwide problem having an impact on the financial performance and efficient operations of an organization and the quality of care delivered to patients. ${ }^{[3]}$ However, this applies to nursing generally and not specifically to nurse midwives and neonatal nurses. This study sought to explore the factors that nurses working in obstetric units associate with their job satisfaction.

\subsection{Research objectives}

- To explore the factors that influence the job satisfaction of nurses working in the obstetric units in public hospitals in Kenya.

- To examine the relationship between nurses' age, gender, work experience and professional experience with their job satisfaction.

\subsection{Theoretical framework}

The study utilized the Herzberg theory of motivation as the theoretical framework which states that the intrinsic and extrinsic factors motivate the individual to satisfy their own needs. This theory was developed following a study of 200 engineers and accountants from 9 different companies. ${ }^{[4]}$ It established that the factors that cause satisfaction and presumably motivation factors were different from those causing job dissatisfaction.

\section{MethodS}

\subsection{Design}

The researcher used a cross-sectional survey design to explore the factors influencing the job satisfaction of nurses working in obstetric units in two public hospitals in Kenya, Africa. Cross-sectional studies examine data at one point in time, that is, data collected on only one occasion with the same subjects rather than with the same subjects at several time points. ${ }^{[5,6]}$ The design also involves the collection of data from groups of people who are at different stages of their experience of a particular phenomenon. ${ }^{[7]}$ Data were collected about demographic characteristics like gender age, professional qualification and work experience of the nurses working in obstetrics units with different aspects of the work

Published by Sciedu Press environment. A cross-sectional study is efficient and economical which is also one of the reasons the design was chosen. Also, there was no need to worry about subjects dropping out during the course of the study. However, there are challenges in inferring changes and trends over time using this. ${ }^{[5,6]}$ The Survey collected data regarding nurses' actions, knowledge, intentions, opinions and attitudes by means of self-report. ${ }^{[6,8]}$

\subsection{Study setting}

Data were collected from the obstetric departments of two public hospitals in Kenya. One hospital was at level five and had a bed capacity of 265; while the other was at level four and had a bed capacity of 316 . The obstetric units are composed of the ante-natal, labour, postnatal and newborn subunits. Of the nurses working in these units, $65 \%$ of them are diploma holders, $30 \%$ are certificate holders and $5 \%$ are degree holders. ${ }^{[9,10]}$

\subsection{Data collection tools}

The researcher used the work quality index (WQI) tool which was developed in order to assess the job satisfaction of nurses who worked in acute care settings. ${ }^{[11]}$ The tool comprises 38 items organized into six subscales that measure nurses' satisfaction with their work environment as well as with the job properties of autonomy, work worth, professional relationships, role enactment and benefits measured on a scale of 1-7 with 1 being not satisfied and 7 being satisfied. It is valid, reliable and easy to use instrument with a correlation coefficient of $0.94 .^{[11]}$ A demographic questionnaire was designed to obtain data on gender, age, professional qualification, years of nursing experience and years of experience in the obstetric units. The researcher assessed the face and content validity of the demographic questionnaire a pilot study and peer reviewing where the questionnaires were given to nurse researchers with research experience to comment on the extent to which the questionnaire met the research objectives.

\subsection{Data collection method}

Data were collected from the obstetric department of two public hospitals. They were collected for two weeks during the morning and the afternoon shifts so as to target all the nurses on duty during those shifts. The researcher was not known to the participants therefore there was no chance of the researcher influencing the study results. Two research assistants who had no background in nursing together with the researcher helped in explaining the information sheet to the participants and later they distributed the questionnaires. These assistants were first trained on the data collection procedures to ensure they understood the data collection tools and the data collection method. 


\subsection{Research ethics}

Ethical approval was sought from the University of Dundee and the University of Eastern Africa, Baraton. Authority to carry out the research was sought from the National Council of Science and Technology, Kenya and from the hospital administration. Each participant was also provided with an information sheet detailing the purpose of the study, the right to choose to or not to participate and the right to withdraw at any time. Participants were assured of confidentiality and anonymity was ensured by avoiding use of their names but instead the questionnaires were coded. Each consenting participant was provided with a consent form and requested to sign as a sign of consent.

\subsection{Inclusion and exclusion criteria}

The participants were all trained nurses working in the obstetric units in two public hospitals. They had trained at either certificate, diploma or degree level. They had to be working in these units and had to be on duty at the time of data collection.

\subsection{Recruitment and sampling}

Convenience sampling was used as every nurse on duty during the shifts over the two weeks was included in the sample. In convenience sampling subjects are picked because of their easy accessibility and proximity to the researcher. The problem with this sampling method is sampling bias, the sample is not representative of the entire population and it is not possible to generalize and make inference about the entire population resulting in a low external validity of the study.

\subsection{Data analysis}

A codebook was prepared and the responses in the demographic questionnaire were coded using the SPSS version 20. Data entry and cleaning was then undertaken. The quantitative data obtained from the questionnaire was analyzed using descriptive statistics. This involved the use of frequencies, percentages, mean and standard deviation and range. Descriptive statistical techniques reduce data to manageable proportions by summarizing them and they also describe various characteristics of the data under study. ${ }^{[5]}$

The items in the Work Quality Index questionnaire were organized into six subscales which included the professional work environment, autonomy of practice, work worth to self and others, professional relationships, professional role enactment and benefits. The individual items that were in each scale are as shown in Table 1.

\section{FindingS}

\subsection{Response rate}

Out of the 81 questionnaires that were distributed, 67 were returned. However, only 62 of them were used for data analysis as two of them had the participants only completing the demographic data and three of them had the participants circling all the options in the WQI questionnaire.

\subsection{Demographic of participants}

There were more female nurses $(n=55 ; 88.7 \%)$ than male nurses $(n=7 ; 11.3 \%)$ (see Table 2$)$. Most participants were in the $36-45$ years age group $(n=29 ; 46.8 \%)$, followed by those who were above 45 years $(n=17 ; 27.4 \%)$, then those who were $25-35$ years $(n=12 ; 19.4 \%)$, and the least were those aged below 25 years $(n=4 ; 6.5 \%)$. Most of the nurses were diploma holders $(n=49 ; 79 \%)$. Those trained at the certificate level were $7(11.3 \%)$ and those trained at the degree level were the minority at $6(9.7 \%)$. Thirty two of the nurses $(51.6 \%)$ had worked as nurses for 10-20 years, 17 of them $(27.4 \%)$ had worked for $>20$ years. Those who had worked for $<10$ years were $13(21 \%)$. Twenty three of the nurses $(37.1 \%)$ had worked for between 10 and 20 years which corresponded with the highest number that had worked as nurses. $30(48.4 \%)$ of them had worked for $<10$ years and 9 $(14.5 \%)$ had worked for $>20$ years in the obstetric units (see Table 2)

\subsection{Age of respondents}

Most of the respondents were $36-45$ years old (see Figure 1).

\subsection{Job satisfaction levels on the questionnaire items}

From the individual items (see Table 3), the nurses were most satisfied with the perception that the work associated with their position provides them with the opportunity to be of service to others $(\mathrm{M}=5.3, \mathrm{SD}=1.5)$. They were satisfied with their own sense of achievement $(\mathrm{M}=4.5, \mathrm{SD}=2.7)$, having a variety of clinical challenges $(\mathrm{M}=4.4, \mathrm{SD}=1.4)$, and having adequate in-service opportunities $(\mathrm{M}=4.1, \mathrm{SD}=$ 1.4). Adequate vacation, adequate sick leave, good working relationship with peers and making contribution to the profession had a satisfaction level of 4 with a standard deviation of $1.4,1.4,1.5$ and 1.3 respectfully (see Table 3 ). However, the nurses were dissatisfied with some items that scored low on the satisfaction scale. These included receiving enough time to complete indirect patient care tasks $(\mathrm{M}=2, \mathrm{SD}=$ $1.1)$, adequate funding for health care cover $(\mathrm{M}=2.1, \mathrm{SD}$ $=1.3)$, satisfactory salary $(\mathrm{M}=2.2, \mathrm{SD}=1.3)$, support for work from nurses on other shifts $(\mathrm{M}=2.3, \mathrm{SD}=1.2)$ and receiving adequate respect from nurses in other shifts $(\mathrm{M}=$ $2.3, \mathrm{SD}=1.4)$. 
Table 1. Main subscales for job satisfaction from the WQI questionnaire

\begin{tabular}{|c|c|c|}
\hline Subscale & Number & Individual items making up the subscale \\
\hline \multirow{8}{*}{$\begin{array}{l}\text { Professional } \\
\text { work } \\
\text { environment }\end{array}$} & 2.03 & You receive adequate praise for work well done from nursing administration \\
\hline & 4.07 & The nursing practice environment allows opportunities to receive adequate respect from nurses in other units \\
\hline & 5.01 & The hospital organizational structure allows you to have a voice in policy making for nursing services \\
\hline & 5.02 & The hospital organizational structure allows you to have a voice in overall hospital policy making \\
\hline & 5.03 & The hospital organizational structure facilitates patient care \\
\hline & 8.02 & Nursing service provides adequate opportunities for advancement \\
\hline & 9.01 & Your job offers opportunity for professional growth \\
\hline & 9.08 & Your job offers adequate in-service opportunities \\
\hline \multirow{5}{*}{$\begin{array}{l}\text { Autonomy of } \\
\text { practice }\end{array}$} & 4.01 & The nurse practice environment allows you to make autonomous nursing care decisions \\
\hline & 4.02 & The nurse practice environment allows you to be fully accountable for nursing care decisions \\
\hline & 4.03 & The nurse practice environment encourages you to make adjustments in your nursing practice to suit patient needs \\
\hline & 4.04 & The nurse practice environment Provides a stimulating intellectual environment \\
\hline & 4.06 & The nurse practice environment Promotes a high level of clinical competence in your unit \\
\hline \multirow{4}{*}{$\begin{array}{l}\text { Work worth } \\
\text { to self and } \\
\text { others }\end{array}$} & 1.01 & The work associated with your position allows you to make contribution to the hospital \\
\hline & 1.02 & The work associated with your position allows you to make contribution to the profession \\
\hline & 1.03 & The work associated with your position allows you to make contribution to your own sense of achievement \\
\hline & 3.01 & The work associated with your position provides you with opportunity to use a full range of nursing skills \\
\hline \multirow{8}{*}{$\begin{array}{l}\text { Professional } \\
\text { relationships }\end{array}$} & 2.01 & You receive adequate praise for work well done from your peers \\
\hline & 2.02 & You receive adequate praise for work well done from hospital physicians \\
\hline & 6.03 & You receive support for your work from nurses on other shifts \\
\hline & 6.04 & You receive support from your peers for your nursing decisions \\
\hline & 6.05 & You receive support from physicians for your nursing decisions \\
\hline & 7.01 & Good working relationships exist between you and your supervisor \\
\hline & 7.02 & Good working relationships exist between you and your peers \\
\hline & 7.03 & Good working relationships exist between you and physicians \\
\hline \multirow{5}{*}{$\begin{array}{l}\text { Professional } \\
\text { role } \\
\text { enactment }\end{array}$} & 3.02 & The work associated with your position provides you with a variety of clinical challenges \\
\hline & 3.03 & The work associated with your position provides you with the opportunity to be of service to others \\
\hline & 4.05 & The nursing practice environment Provides time to engage in research if you want \\
\hline & 6.01 & You receive enough time to complete patient Physical care tasks \\
\hline & 6.02 & You receive enough time to complete indirect patient care tasks \\
\hline \multirow{8}{*}{ Benefits } & 8.02 & Nursing service gives clear direction about advancement \\
\hline & 8.03 & Nursing service decides advancement for nurses fairly \\
\hline & 9.02 & Your job offers satisfactory salary \\
\hline & 9.03 & Your job offers adequate funding for health care cover \\
\hline & 9.04 & Your job offers adequate additional financial benefits other than salary \\
\hline & 9.05 & Your job offers a satisfactory work hour pattern \\
\hline & 9.06 & Your job offers adequate vacation \\
\hline & 9.07 & Your job offers adequate sick leave \\
\hline
\end{tabular}

\subsection{Satisfaction with main subscales}

Nurses experienced the highest satisfaction with work worth to self and others which had a mean score of 3.93 ( $\mathrm{SD}=$ 1.28). This was notably still far from the highest score on the questionnaire which was 7 . The rest of the scores in decreasing order were professional role enactment $(\mathrm{M}=3.29$, SD $=0.93)$, benefits $(\mathrm{M}=3.05, \mathrm{SD}=0.97)$, professional work environment $(\mathrm{M}=2.97, \mathrm{SD}=1.14)$, autonomy of practice $(\mathrm{M}=2.95, \mathrm{SD}=1.27)$ and professional relationships $(\mathrm{M}=$ $2.90, \mathrm{SD}=1.19)$ (see Table 4). The tool (WQI) had a reliability coefficient of 0.93 . The individual subscales also had high reliability coefficients which were: professional work environment (0.90), autonomy of practice (0.95), work worth to self and others (0.93), professional relationships (0.72), Published by Sciedu Press professional role enactment $(0.80)$ and benefits $(0.83)$.

\subsection{Comparison between job satisfaction and nurses de- mographic characteristics \\ 3.6.1 Comparison between gender and satisfaction with main subscales}

There were no significant differences in satisfaction with: professional work environment scores for males $(\mathrm{M}=3.49$, $\mathrm{SD}=1.42)$ and females $(\mathrm{M}=2.92, \mathrm{SD}=1.10 ; t[59]=1.26$, $p=.130,2$-tailed); work worth to self and others male $(\mathrm{M}=$ $4.43, \mathrm{SD}=1.49)$ and females $(\mathrm{M}=3.88, \mathrm{SD}=1.27 ; t[59]=$ $1.07, p=.790,2$-tailed); professional relationships male (M $=3.49, \mathrm{SD}=1.40)$ and females $(\mathrm{M}=2.84, \mathrm{SD}=1.16 ; t[59]$ $=1.36, p=.350,2$-tailed $)$ and benefits male $(\mathrm{M}=3.14, \mathrm{SD}$ 
$=1.29)$ and females $(\mathrm{M}=3.04, \mathrm{SD}=0.94 ; t[59]=0.27, p=$ .247, 2-tailed) (see Table 5).

Table 2. Demographics of participants

\begin{tabular}{lcc}
\hline Baseline Characteristics & Freq. & \% \\
\hline Sex & 7 & 11.3 \\
Male & 55 & 88.7 \\
Female & & \\
Age in Years & 4 & 6.5 \\
$\quad<25$ & 12 & 19.4 \\
$25-35$ & 29 & 46.8 \\
$36-45$ & 17 & 27.4 \\
$45+$ & \\
Professional qualification & 7 & 11.3 \\
Certificate level (ECN/ECHN) & 49 & 79.0 \\
Diploma level (KRN/KRM/KRCHN) & 6 & 9.7 \\
Degree level (BSC (N) & & \\
How long have you worked as a nurse (in years) & \\
$<10$ & 13 & 21 \\
$10-20$ & 32 & 51.6 \\
$>20$ & 17 & 27.4 \\
How long have you worked in obstetric unit (in years) \\
$<10$ & 30 & 48.4 \\
$10-20$ & 23 & 37.1 \\
$>20$ & 9 & 14.5 \\
\hline
\end{tabular}

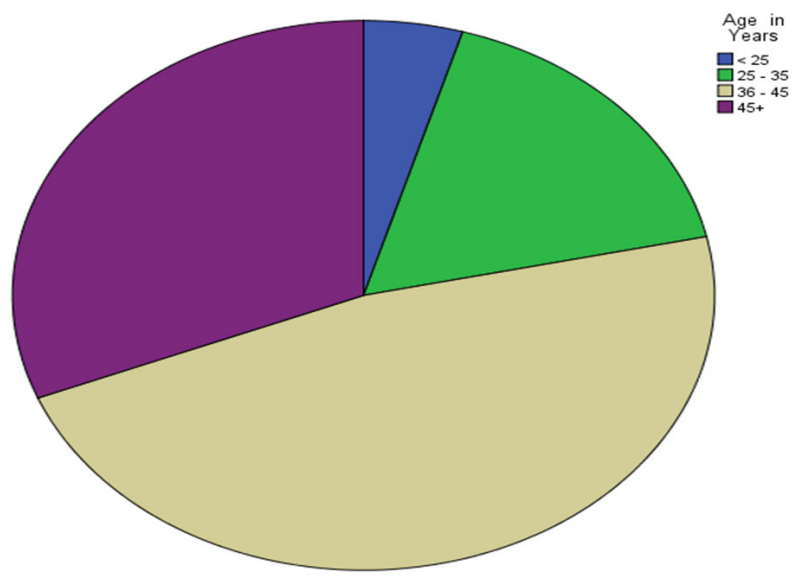

Figure 1. A pie chart illustrating the age of the respondents

However, there were significant differences in scores for males and for females when compared against autonomy of practice (see Figure 2) and professional role enactment (see Figure 3) with males scoring significantly higher than females. Against autonomy of practice, the scores were: male $(\mathrm{M}=3.54, \mathrm{SD}=1.78)$ and females $(\mathrm{M}=2.90, \mathrm{SD}=1.18 ; t$ $(59)=0.93, p=.03,2$-tailed) and against professional role enactment, the scores were: male $(\mathrm{M}=3.80, \mathrm{SD}=1.31)$ and females $(\mathrm{M}=3.24, \mathrm{SD}=0.87 ; t(59)=1.11, p=.03,2$-tailed $)$ (see Table 5). The magnitude of the differences in the means for autonomy (mean difference $=.64,95 \% \mathrm{CI}:-1.00$ to 2.30 ) was very small (eta squared $=.01$ ). The magnitude of the differences in the means for professional role enactment (mean difference $=.56,95 \%$ CI: -0.65 to 1.78 ) was very small (eta squared $=.02$ ).

The male nurses were significantly more satisfied with autonomy of practice than the female nurses (see Figure 2).

The satisfaction with the professional role enactment was more significant for males than the female nurses (see Figure $3)$.

\subsubsection{Comparison between age and satisfaction with the main subscales}

The difference in satisfaction with professional work environment and benefits for the four groups was not found to be statically significant (see Table 6). Participants who were above 45 years were significantly more satisfied with autonomy of practice, professional relationships and professional role enactment than those who were below 25 years. Those who were above 45 years were also significantly more satisfied with work worth to self and others than all the other younger age groups. Participants who were $<25$ years, 25 35 years and $36-45$ years did not differ significantly in their satisfaction with any of the subscales.

The older nurses were significantly more satisfied with professional relationships (see Figure 4).

\subsubsection{Comparison between the main subscales and profes- sional qualifications}

The difference in the level of satisfaction with benefits for all the three groups was not found to be statistically significant. However, the certificate holders were significantly more satisfied with professional work environment, autonomy of practice, work worth to self and others (see Table 7) and professional relationships (see Table 7) than both the diploma and the degree holders. The certificate holders were significantly more satisfied with professional role enactment than the diploma holders but not significantly more than the degree holders. Notably, the degree and the diploma holders did not differ significantly in their satisfaction with any of the subscales (see Table 7). The actual differences as indicated by the eta squared were: professional work environment (.19), autonomy of practice (.25), work worth to self and others (.19), professional relationships (.19) and professional role enactment (.13).

\subsubsection{Comparison between the main subscale and years of experience in nursing}

The participants who had worked for $>20$ years as nurses were significantly more satisfied with autonomy of practice 
and work worth to self and others than those who had worked for $<10$ years and 10-20 years (see Table 8). However those who had worked for $<10$ years did not differ significantly with those who had been nurses for between 10 and 20 years in their level of satisfaction. Similarly, the participants who had worked for $>20$ were significantly more satisfied with professional relationships and professional role enactment than those who had worked for $<10$ years. The actual differences were quite large for the autonomy of practice (eta squared $=.15$ ), work worth to self and others (eta squared $=$ .20 ) and professional role enactment (eta squared $=.14$ ) subscales but moderately large for the professional relationships subscale (eta squared $=.11$ ).

Table 3. Job Satisfaction Levels on the questionnaire items

\begin{tabular}{|c|c|c|c|}
\hline Subscale & Individual items making up the subscale & MEAN & STD \\
\hline \multirow{8}{*}{$\begin{array}{l}\text { Professional } \\
\text { work } \\
\text { environment }\end{array}$} & You receive adequate praise for work well done from nursing administration & 2.4 & 1.6 \\
\hline & The nursing practice environment allows opportunities to receive adequate respect from nurses in other units & 2.3 & 1.4 \\
\hline & The hospital organizational structure allows you to have a voice in policy making for nursing services & 2.3 & 1.4 \\
\hline & The hospital organizational structure allows you to have a voice in overall hospital policy making & 2.5 & 1.6 \\
\hline & The hospital organizational structure facilitates patient care & 2.8 & 1.5 \\
\hline & Nursing service provides adequate opportunities for advancement & 2.8 & 1.6 \\
\hline & Your job offers opportunity for professional growth & 3.8 & 1.6 \\
\hline & Your job offers adequate in-service opportunities & 4.1 & 1.4 \\
\hline \multirow{5}{*}{$\begin{array}{l}\text { Autonomy } \\
\text { of practice }\end{array}$} & The nurse practice environment allows you to make autonomous nursing care decisions & 3.4 & 1.6 \\
\hline & The nurse practice environment allows you to be fully accountable for nursing care decisions & 2.8 & 1.4 \\
\hline & The nurse practice environment encourages you to make adjustments in your nursing practice to suit patient needs & 2.6 & 1.3 \\
\hline & The nurse practice environment provides a stimulating intellectual environment & 3.3 & 1.3 \\
\hline & The nurse practice environment promotes a high level of clinical competence in your unit & 2.6 & 1.4 \\
\hline \multirow{4}{*}{$\begin{array}{l}\text { Work worth } \\
\text { to self and } \\
\text { others }\end{array}$} & The work associated with your position allows you to make contribution to the hospital & 3.6 & 1.2 \\
\hline & The work associated with your position allows you to make contribution to the profession & 4.0 & 1.3 \\
\hline & The work associated with your position allows you to make contribution to your own sense of achievement & 4.5 & 2.7 \\
\hline & The work associated with your position provides you with opportunity to use a full range of nursing skills & 3.9 & 1.5 \\
\hline \multirow{8}{*}{$\begin{array}{l}\text { Professional } \\
\text { relationships }\end{array}$} & You receive adequate praise for work well done from your peers & 3.3 & 1.7 \\
\hline & You receive adequate praise for work well done from hospital physicians & 2.5 & 1.6 \\
\hline & You receive support for your work from nurses on other shifts & 2.3 & 1.2 \\
\hline & You receive support from your peers for your nursing decisions & 3.8 & 1.7 \\
\hline & You receive support from physicians for your nursing decisions & 2.6 & 1.4 \\
\hline & Good working relationships exist between you and your supervisor & 3.2 & 1.5 \\
\hline & Good working relationships exist between you and your peers & 4.0 & 1.5 \\
\hline & Good working relationships exist between you and physicians & 2.6 & 1.6 \\
\hline \multirow{5}{*}{$\begin{array}{l}\text { Professional } \\
\text { role } \\
\text { enactment }\end{array}$} & The work associated with your position provides you with a variety of clinical challenges & 4.4 & 1.4 \\
\hline & The work associated with your position provides you with the opportunity to be of service to others & 5.3 & 1.5 \\
\hline & The nursing practice environment Provides time to engage in research if you want & 2.4 & 1.3 \\
\hline & You receive enough time to complete patient Physical care tasks & 2.5 & 1.3 \\
\hline & You receive enough time to complete indirect patient care tasks & 2.0 & 1.1 \\
\hline \multirow{8}{*}{ Benefits } & Nursing service gives clear direction about advancement & 3.2 & 1.4 \\
\hline & Nursing service decides advancement for nurses fairly & 2.7 & 1.4 \\
\hline & Your job offers satisfactory salary & 2.2 & 1.3 \\
\hline & Your job offers adequate funding for health care cover & 2.1 & 1.3 \\
\hline & Your job offers adequate additional financial benefits other than salary & 2.4 & 1.6 \\
\hline & Your job offers a satisfactory work hour pattern & 3.8 & 1.6 \\
\hline & Your job offers adequate vacation & 4.0 & 1.4 \\
\hline & Your job offers adequate sick leave & 4.0 & 1.4 \\
\hline
\end{tabular}

3.6.5 Comparison between summary of the main subscales and years of experience in the obstetric units

A one-way group analysis of variance was conducted to explore the impact of job experience in the obstetric units on levels of satisfaction with professional work environment, autonomy of practice, work worth to self and others, profes- sional relationships, professional role enactment and benefits. Eta squared was also calculated to determine the effect size which indicated the magnitude of the differences that were obtained. Post-hoc comparisons using the Tukey HSD was conducted to determine where the actual differences were. 
Table 4. Summary of the main scores for job satisfaction subscales

\begin{tabular}{llllll}
\hline Subscale & $\mathbf{n}$ & Mean & SD & Range & Cronbach's alpha \\
\hline Professional work environment & 62 & 2.97 & 1.14 & 4.63 & .90 \\
Autonomy of practice & 62 & 2.95 & 1.27 & 4.80 & .95 \\
Work worth to self and others & 62 & 3.93 & 1.28 & 4.75 & .93 \\
Professional relationships & 62 & 2.90 & 1.19 & 4.88 & .72 \\
Professional role enactment & 62 & 3.29 & 0.93 & 4.60 & .80 \\
Benefits & 62 & 3.05 & 0.97 & 5.00 & .83 \\
\hline
\end{tabular}

Table 5. Independent samples $t$-test for the relationship between gender and the six subscales

\begin{tabular}{|c|c|c|c|c|}
\hline \multirow{3}{*}{ Subscale } & \multicolumn{2}{|l|}{ Gender } & \multirow{3}{*}{$t$-statistic } & \multirow{3}{*}{$p$-value } \\
\hline & Male $(n=7)$ & Female $(n=55)$ & & \\
\hline & Mean (SD) & Mean (SD) & & \\
\hline professional work environment & $3.49(1.42)$ & $2.92(1.10)$ & 1.26 & .130 \\
\hline Autonomy of practice & $3.54(1.78)$ & $2.90(1.18)$ & 0.93 & .030 \\
\hline Work worth to self and others & $4.43(1.49)$ & $3.88(1.27)$ & 1.07 & .790 \\
\hline Professional relationships & $3.49(1.40)$ & $2.84(1.16)$ & 1.36 & .350 \\
\hline Professional role enactment & $3.80(1.31)$ & $3.24(0.87)$ & 1.11 & .030 \\
\hline Benefits & $3.14(1.29)$ & $3.04(0.94)$ & 0.27 & .247 \\
\hline
\end{tabular}

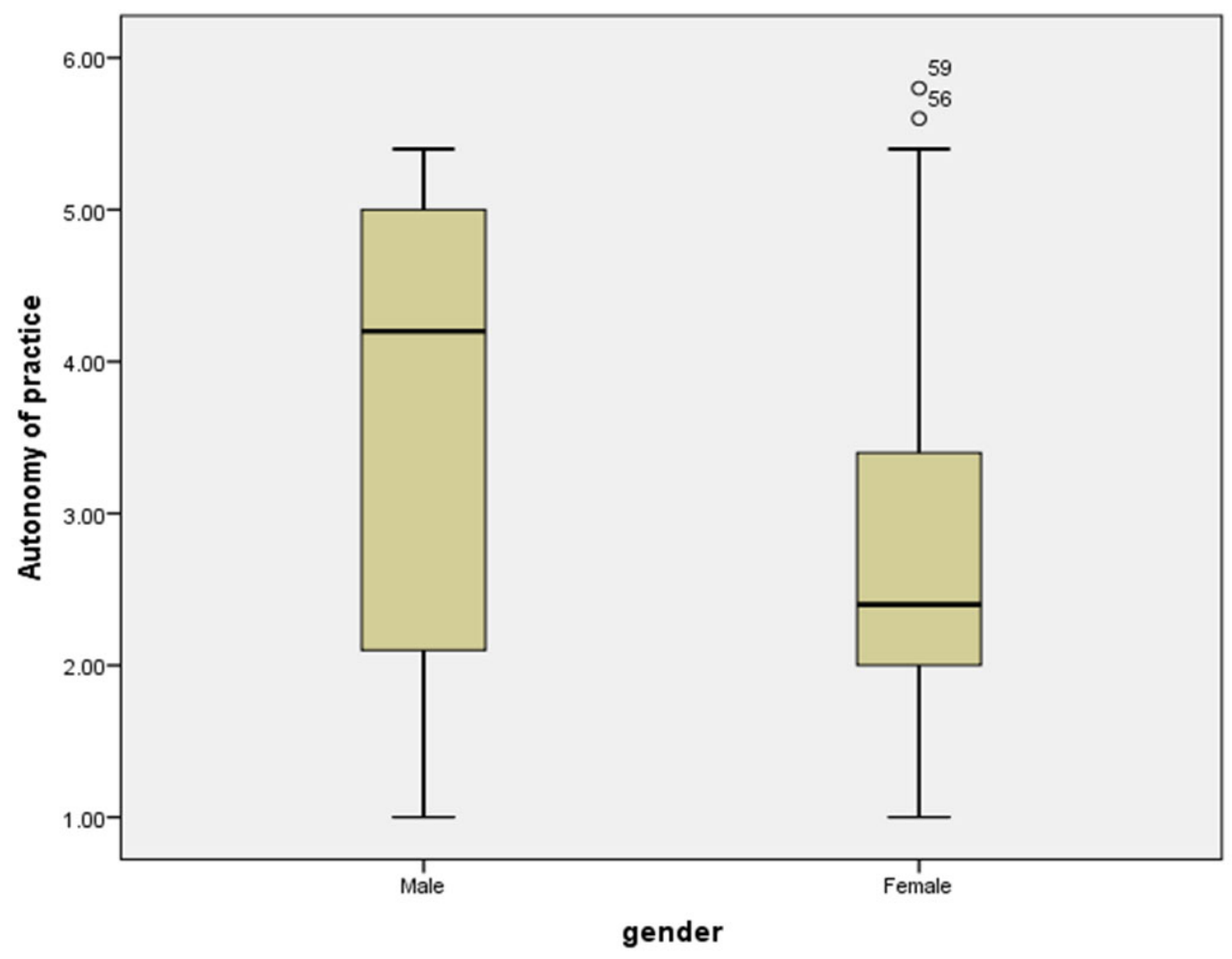

Figure 2. Comparison between gender and satisfaction with autonomy of practice

The difference in satisfaction with professional relationships and benefits for the three groups was not significant (see Table 9). However, those who had been in the obstetric units for $>20$ years showed more satisfaction with professional work environment and autonomy of practice and work worth to self and others as compared to the other groups. Those 
who had worked for $<10$ years demonstrated less satisfaction with professional role enactment than the other groups. The actual differences were quite large for autonomy of practice (eta squared $=.17$ ), work worth to self and others (eta squared
$=.21$ ) and professional role enactment (eta squared $=.15$ ) but only moderately large for professional work environment (eta squared $=.11)$.

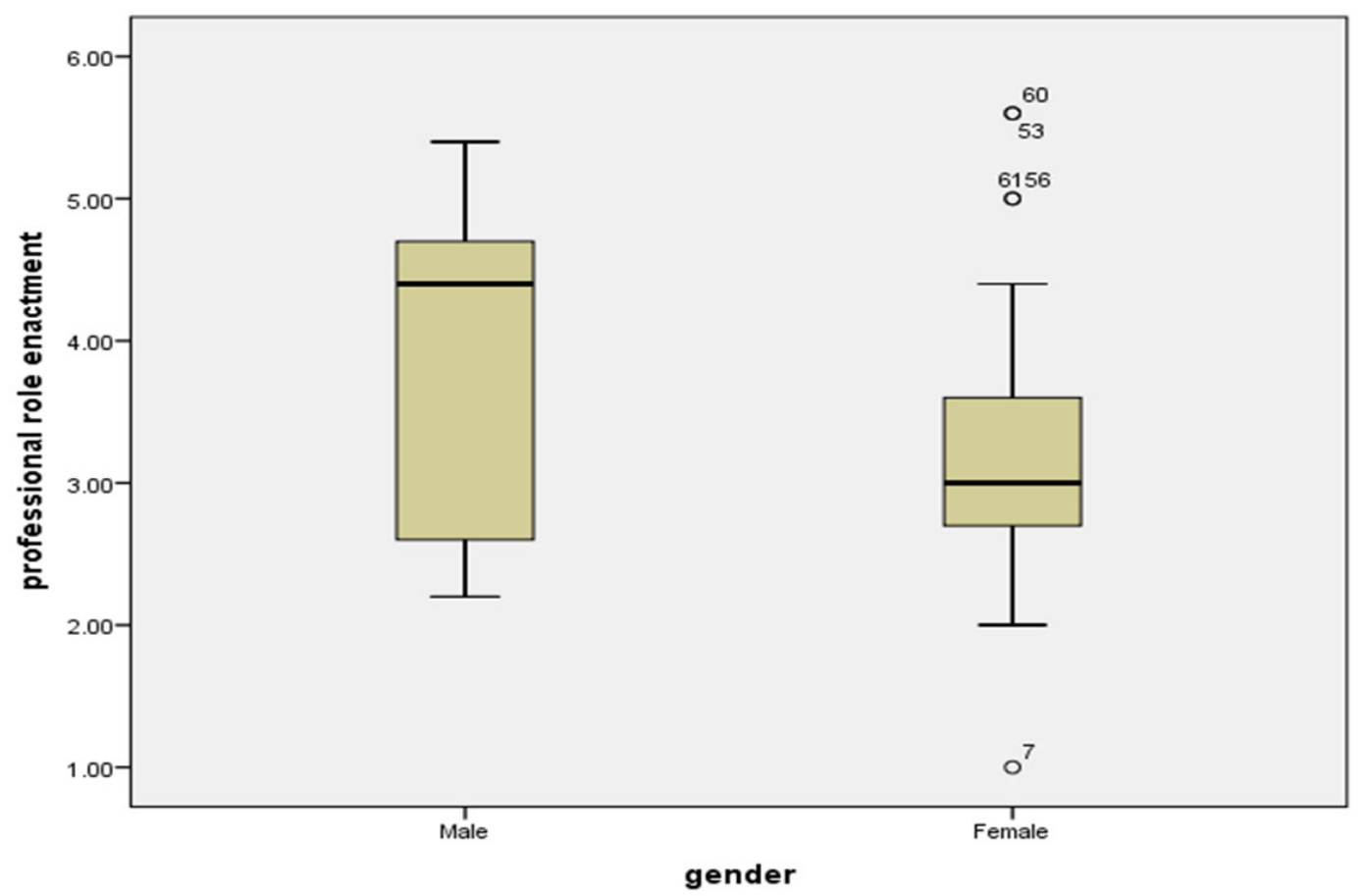

Figure 3. Comparison between gender and professional role enactment

\subsection{Pearson product-moment correlation of the main job satisfaction subscales}

There was a strong positive relationship between professional work environment and autonomy of practice $(r=.86, p<$ $.001)$, work worth to self and others $(r=.63, p<.001)$, professional relationships $(r=.91, \mathrm{n}=62, p<.001)$, professional role enactment $(r=.75, p<.001)$ and benefits $(r=.71$, $p=.001)($ see Table 10).

Autonomy of practice had a strong positive correlation with all the other subscales: professional work environment $(r=$ $.86, p<.001)$, work worth to self and others $(r=.76, p<$ $.001)$, professional relationships $(r=.83, p<.001)$ professional role enactment $(r=.82, p<.001)$ and benefits $(r=.50$, $p<.001)$. There was a positive strong correlation between work worth to self and others and professional work environment, autonomy of practice, professional relationships $(r=$ $.66, p<.001)$ and professional role enactment $(r=.71, p<$ $.001)$. However, there was only a medium positive correlation between work worth to self and others and benefits ( $r=$ $.39, p<.001)$. Professional relationships had a strong positive relationship with professional role enactment $(r=.76$, $p<.001)$ and benefits $(r=.66, p<.001)$. Professional role Published by Sciedu Press enactment had a medium positive relationship with benefits $(r=.49, p<.001)$.

\section{Discussion}

\subsection{Reliability of the tool}

The tool (WQI) had a reliability coefficient of 0.93 . The original tool had a very similar correlation coefficient of 0.94 (Whitley and Putzier 1994). A reliability coefficient of .93 is acceptable. ${ }^{[5,8]}$

The individual subscales also had high reliability coefficients which were: professional work environment (0.90), autonomy of practice (0.95), work worth to self and others (0.93), professional relationships (0.72), professional role enactment $(0.80)$ and benefits $(0.83)$. The original reliability coefficients reported by Whitley and Putzier (1994) were: professional work environment $(0.87)$, autonomy of practice $(0.84)$, work worth to self and others $(0.79)$, professional relationships $(0.80)$, professional role enactment $(0.72)$ and benefits $(0.79)$.

\subsection{Demographic characteristics}

Most of the nurses were females. This was consistent with the national figures where $77 \%$ of Kenya's nurses are female and $23 \%$ are male, ${ }^{[12]}$ though the current sample had fewer 
males than the national sample. It is possible that there are fewer male nurses being deployed into the obstetric units, but the researcher could not establish this to be true. Men are still underrepresented in nursing. ${ }^{[13]}$ In Canada for example, the male nurses identified certain hindrances to joining nursing to include sexual stereotypes, lack of recruitment strategies, nursing as a female-oriented profession and a lack of male role models in the media. Men are about $5.8 \%$ of registered nurses in Canada; $10 \%$ in England and $20 \%$ in Italy. ${ }^{[13,14]}$ There were fewer younger nurses than older nurses. This is partly because the obstetric units are specialty areas that require experience and specific training. The younger nurses may not have the experience needed to be deployed to such areas. Currently there are fewer hospitals who train nurse midwives $^{[15]}$ as the others are trained as general nurses who will take time before they are deployed to the obstetric units. Further, data from Kenya Health Workforce ${ }^{[12]}$ indicate that five percent of nurses are between 50 and 60 years old. Those between 41 and 50 years account for $31 \%$. The rest are below 40 years old. The issue of retention cannot be under estimated as Gross et al. ${ }^{[16]}$ found that from 1999 to 2007 , six percent of Kenyan nurses showed intention to out-migrate. About half of these had not worked for more than 10 years. These were the diploma and the degree holders who are also young and this lowers the number of younger nurses in an aging nursing workforce. ${ }^{[16]}$

Table 6. Mean scores of levels of satisfaction with the main subscales for the different age groups

\begin{tabular}{|c|c|c|c|c|}
\hline Subscales & Age group & $\mathbf{N}$ & mean & Std. Deviation \\
\hline \multirow{5}{*}{ Professional work environment } & $<25$ & 4 & 2.10 & .28 \\
\hline & $25-35$ & 12 & 2.61 & .65 \\
\hline & $36-45$ & 29 & 3.00 & 1.09 \\
\hline & $45+$ & 17 & 3.36 & 1.46 \\
\hline & Total & 62 & 2.97 & 1.14 \\
\hline \multirow{5}{*}{ Autonomy of practice } & $<25$ & 4 & 1.85 & .66 \\
\hline & $25-35$ & 12 & 2.53 & .66 \\
\hline & $36-45$ & 29 & 2.83 & 1.24 \\
\hline & $45+$ & 17 & 3.69 & 1.42 \\
\hline & Total & 62 & 2.95 & 1.27 \\
\hline \multirow{5}{*}{ Work worth to self and others } & $<25$ & 4 & 2.44 & .38 \\
\hline & $25-35$ & 12 & 3.46 & .99 \\
\hline & $36-45$ & 29 & 3.84 & 1.11 \\
\hline & $45+$ & 17 & 4.79 & 1.37 \\
\hline & Total & 62 & 3.93 & 1.28 \\
\hline \multirow{5}{*}{ Professional relationships } & $<25$ & 4 & 1.66 & .47 \\
\hline & $25-35$ & 12 & 2.57 & .77 \\
\hline & $36-45$ & 29 & 2.96 & 1.10 \\
\hline & $45+$ & 17 & 3.34 & 1.45 \\
\hline & Total & 62 & 2.90 & 1.19 \\
\hline \multirow{5}{*}{ Professional role enactment } & $<25$ & 4 & 2.25 & .84 \\
\hline & $25-35$ & 12 & 3.02 & .55 \\
\hline & $36-45$ & 29 & 3.23 & .92 \\
\hline & $45+$ & 17 & 3.84 & .91 \\
\hline & Total & 62 & 3.29 & .93 \\
\hline \multirow{5}{*}{ Benefits } & $<25$ & 4 & 2.13 & .37 \\
\hline & $25-35$ & 12 & 2.86 & .55 \\
\hline & $36-45$ & 29 & 3.27 & 1.02 \\
\hline & $45+$ & 17 & 3.01 & 1.09 \\
\hline & Total & 62 & 3.05 & .97 \\
\hline
\end{tabular}




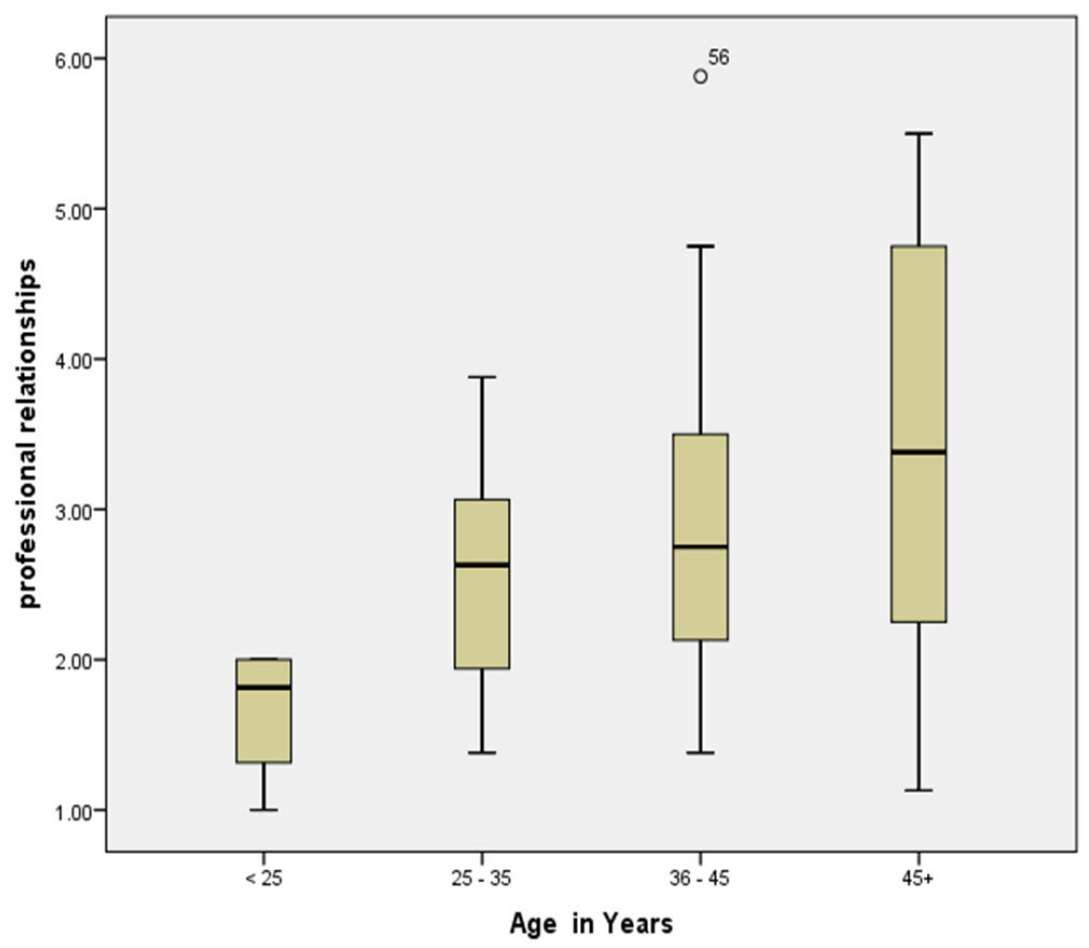

Figure 4. Comparison between age and professional relationships

Table 7. The mean scores of levels of satisfaction with the main subscales for the three groups according to professional qualifications

\begin{tabular}{|c|c|c|c|c|}
\hline Subscale & Professional qualification & $\mathbf{N}$ & Mean & Std. deviation \\
\hline \multirow{4}{*}{ Professional work environment } & Certificate & 7 & 4.33 & 1.37 \\
\hline & Diploma & 49 & 2.82 & .10 \\
\hline & Degree & 6 & 2.52 & .10 \\
\hline & Total & 62 & 2.97 & 1.14 \\
\hline \multirow{4}{*}{ Autonomy of practice } & Certificate & 7 & 4.71 & 1.24 \\
\hline & Diploma & 49 & 2.69 & 1.08 \\
\hline & Degree & 6 & 2.93 & 1.29 \\
\hline & Total & 62 & 2.94 & 1.27 \\
\hline \multirow{4}{*}{ Work worth to self and others } & Certificate & 7 & 5.39 & 1.48 \\
\hline & Diploma & 49 & 3.82 & 1.15 \\
\hline & Degree & 6 & 3.12 & .97 \\
\hline & Total & 62 & 3.93 & 1.28 \\
\hline \multirow{4}{*}{ Professional relationships } & Certificate & 7 & 4.30 & 1.33 \\
\hline & Diploma & 49 & 2.77 & 1.02 \\
\hline & Degree & 6 & 2.34 & 1.28 \\
\hline & Total & 62 & 2.90 & 1.19 \\
\hline \multirow{4}{*}{ Professional role enactment } & Certificate & 7 & 4.23 & 1.24 \\
\hline & Diploma & 49 & 3.18 & .78 \\
\hline & Degree & 6 & 3.10 & 1.22 \\
\hline & Total & 62 & 3.29 & .93 \\
\hline \multirow{4}{*}{ Benefits } & Certificate & 7 & 3.16 & 1.18 \\
\hline & Diploma & 49 & 3.06 & .94 \\
\hline & Degree & 6 & 2.86 & 1.14 \\
\hline & Total & 62 & 3.05 & .97 \\
\hline
\end{tabular}


Table 8. Comparison between the main scores for job satisfaction and job experience in nursing

\begin{tabular}{|c|c|c|c|c|c|}
\hline Subscales & Sum of Squares & df & Mean Square & $\mathbf{F}$ & Sig. \\
\hline \multirow{3}{*}{ Professional work environment } & 7.14 & 2 & 3.57 & & \\
\hline & 72.05 & 59 & 1.22 & 2.92 & .06 \\
\hline & 79.19 & 61 & & & \\
\hline \multirow{3}{*}{ Autonomy of practice } & 14.63 & 2 & 7.31 & & \\
\hline & 83.55 & 59 & 1.42 & 5.17 & .01 \\
\hline & 98.17 & 61 & & & \\
\hline \multirow{3}{*}{ Work worth to self and others } & 20.03 & 2 & 10.02 & & \\
\hline & 80.62 & 59 & 1.37 & 7.33 & .00 \\
\hline & 100.65 & 61 & & & \\
\hline \multirow{3}{*}{ Professional relationships } & 9.60 & 2 & 4.80 & & \\
\hline & 76.18 & 59 & 1.29 & 3.72 & .03 \\
\hline & 85.78 & 61 & & & \\
\hline \multirow{3}{*}{ Professional role enactment } & 7.63 & 2 & 3.81 & & \\
\hline & 45.15 & 59 & .77 & 4.99 & .01 \\
\hline & 52.77 & 61 & & & \\
\hline \multirow{3}{*}{ Benefits } & 2.80 & 2 & 1.40 & & \\
\hline & 54.48 & 59 & .92 & 1.51 & .23 \\
\hline & 57.27 & 61 & & & \\
\hline
\end{tabular}

Table 9. Comparison between summary of the main scores for job satisfaction and job experience in obstetric unit

\begin{tabular}{|c|c|c|c|c|c|}
\hline Subscales & Sum of Squares & df & Mean Square & $\bar{F}$ & Sig. \\
\hline \multirow{3}{*}{ Professional work environment } & 8.53 & 2 & 4.27 & & \\
\hline & 70.66 & 59 & 1.20 & 3.56 & .04 \\
\hline & 79.19 & 61 & & & \\
\hline \multirow{3}{*}{ Autonomy of practice } & 16.43 & 2 & 8.22 & & \\
\hline & 81.74 & 59 & 1.39 & 5.93 & .01 \\
\hline & 98.17 & 61 & & & \\
\hline \multirow{3}{*}{ Work worth to self and others } & 21. & 2 & 10.64 & & \\
\hline & 79.38 & 59 & 1.35 & 7.91 & .00 \\
\hline & 100.65 & 61 & & & \\
\hline \multirow{3}{*}{ Professional relationships } & 7.03 & 2 & 3.51 & & \\
\hline & 78.75 & 59 & 1.34 & 2.63 & .08 \\
\hline & 85.78 & 61 & & & \\
\hline \multirow{3}{*}{ Professional role enactment } & 7.96 & 2 & 3.98 & & \\
\hline & 44.82 & 59 & .76 & 5.24 & .01 \\
\hline & 52.77 & 61 & & & \\
\hline \multirow{3}{*}{ Benefits } & 1.15 & 2 & .57 & & \\
\hline & 56.13 & 59 & .95 & .60 & .55 \\
\hline & 57.27 & 61 & & & \\
\hline
\end{tabular}

\subsection{Satisfaction with individual items}

The nurses were most satisfied with the perception that their work provides them with the opportunity to serve others, their sense of achievement, having a variety of clinical chal- lenges, and having adequate in-service opportunities. This was an indication that the altruistic nature of nursing has not changed and nurses are more interested in helping the sick meet their daily cares. This adds to an increasing body of 
knowledge where for example, Choi et al. ${ }^{[1]}$ in Hong Kong also expressed that the factors that attract people to nursing include interesting and challenging work and the ability to help others. Similarly, Doef et al. ${ }^{[17]}$ highlighted that pro- viding comfort for patients and the knowing that patients are provided with adequate care were linked to increased job satisfaction. The findings are the same despite cultural differences in the study settings.

Table 10. Correlation of the subscale for job satisfaction

\begin{tabular}{|c|c|c|c|c|c|c|c|}
\hline Subscales & Subscales & $\begin{array}{l}\text { Professional } \\
\text { work } \\
\text { environment }\end{array}$ & $\begin{array}{l}\text { Autonomy } \\
\text { of practice }\end{array}$ & $\begin{array}{l}\text { Work worth } \\
\text { to self and } \\
\text { others }\end{array}$ & $\begin{array}{l}\text { Professional } \\
\text { relation- } \\
\text { ships }\end{array}$ & $\begin{array}{l}\text { Professional } \\
\text { role } \\
\text { enactment }\end{array}$ & Benefits \\
\hline \multirow{3}{*}{$\begin{array}{l}\text { Professional } \\
\text { work } \\
\text { environment }\end{array}$} & Pearson correlation & 1 & $.86 * *$ & $.63^{* *}$ & $.92 * *$ & $.75 * *$ & $.71 * *$ \\
\hline & Sig. (2-tailed) & & .000 & .000 & .000 & .000 & .000 \\
\hline & $\mathrm{N}$ & 62 & 62 & 62 & 62 & 62 & 62 \\
\hline \multirow{3}{*}{$\begin{array}{l}\text { Autonomy of } \\
\text { practice }\end{array}$} & Pearson correlation & & 1 & $.76 * *$ & $.83 * *$ & $.82 * *$ & $.50 * *$ \\
\hline & Sig. (2-tailed) & & & .000 & .000 & .000 & .000 \\
\hline & $\mathrm{N}$ & & 62 & 62 & 62 & 62 & 62 \\
\hline \multirow{3}{*}{$\begin{array}{l}\text { Work worth } \\
\text { to self and } \\
\text { others }\end{array}$} & Pearson correlation & & & 1 & $.66^{* *}$ & $.71 * *$ & $.39 * *$ \\
\hline & Sig. (2-tailed) & & & & .000 & .000 & .000 \\
\hline & $\mathrm{N}$ & & & 62 & 62 & 62 & 62 \\
\hline \multirow{3}{*}{$\begin{array}{l}\text { Professional } \\
\text { relationships }\end{array}$} & Pearson correlation & & & & 1 & $.76 * *$ & $.66 * *$ \\
\hline & Sig. (2-tailed) & & & & & 000 & .000 \\
\hline & $\mathrm{N}$ & & & & 62 & 62 & 62 \\
\hline \multirow{3}{*}{$\begin{array}{l}\text { Professional } \\
\text { role } \\
\text { enactment }\end{array}$} & Pearson correlation & & & & & 1 & $.49 * *$ \\
\hline & Sig. (2-tailed) & & & & & & .000 \\
\hline & $\mathrm{N}$ & & & & & 62 & 62 \\
\hline \multirow{3}{*}{ Benefits } & Pearson correlation & & & & & & 1 \\
\hline & Sig. (2-tailed) & & & & & & \\
\hline & $\mathrm{N}$ & & & & & & 62 \\
\hline
\end{tabular}

**-Correlation is significant at the .001 level (2-tailed)

The nurses in the obstetric units were found to be relatively satisfied with having clinical challenges which are many in the obstetric units and this may be something that nurses look forward to every day. The fact that having adequate in-service opportunities scored relatively higher was commendable. The regulatory body for nurses has in the last one year declared that each nurse shall engage in a minimum of 40 hours of continuing professional development (CPD) per annum before the three yearly relicensure. ${ }^{[15,18,19]}$ This is an increment from a previous 20 hours of CPD every three years and it seems in-service opportunities are still adequate to meet this need. However, the nurses felt they were not getting enough time to accomplish indirect patient care tasks. There is no available data to show why the nurses in this study felt this, but anecdotal evidence indicate that the nurses spend more than half the time carrying out patient documentation and carrying out non-essential nursing tasks like clerical work. Although nurses elsewhere do not appreciate many tasks that are not directly related to patient care. ${ }^{[1,16]}$ There was less satisfaction with satisfactory salary among the nurse midwives in the public hospitals. Nurses working in the non-government sectors in one of the East African countries were more dissatisfied with their pay than their counterparts in the public sector, findings that concurred with those of South African nurses. ${ }^{[20]}$ Among the benefits, the nurses were relatively more satisfied with the hour pattern, sick leave and adequate vacation. Flexibility with scheduling gives them time to attend to other personal matters and nurses are satisfied by convenient job schedules that allow them to meet their personal and family needs. ${ }^{[21]}$

\subsection{Satisfaction with main subscales}

From the six subscales, three were hygiene factors. These were: professional work environment, professional relationships and benefits. The other three were motivation factors: autonomy of practice, work worth to self and others and professional role enactment. The nurses were most satisfied with work worth to self and others, supporting findings by Doef et al. ${ }^{[17]}$ who found that nurses in East Africa feel more accomplished. South African nurses were found to be moderately accomplished Gaki et al. ${ }^{[22]}$ The findings from South Africa can be compared with those in Kenya since there are cultural similarities between the two countries.

The participants in this study felt more satisfied with profes- 
sional role enactment, supporting findings of Hayes et al. ${ }^{[23]}$ through a meta-analysis of studies from different cultures, who found that providing patients with the needed care gives a sense of value and reward to nurses. There was less satisfaction with autonomy of practice. Autonomy of practice is an important aspect of job satisfaction. ${ }^{[2,3,24]}$ It has however been reported worldwide to be actively discouraged by employers $^{[23]}$ and this could be the reason the nurses did not perceive satisfaction with autonomy of practice. The scope of practice as guided by the nursing council of Kenya also discourages nurses from being able to control their own work and having control of their decisions. ${ }^{[15]}$ Nurses are usually expected to operate within the doctors' orders and cannot alter a patient's care without consulting with the doctors. There was relative dissatisfaction with professional relationships. Findings in the western countries indicate that the most satisfying factors for nurses are relationships with peers and physicians. ${ }^{[3]}$ The need for professional relationships for the nurse practitioners in USA may be understandably low ${ }^{[3]}$ because of their autonomous way of practice but it is expected that the nurse midwives in Kenya would find the relationships essential since the nursing patient care tasks are dependent on the medical care.

\subsection{Comparison between gender and job satisfaction}

Male nurses were more satisfied with two subscales; autonomy of practice and professional role enactment than their female counterparts. The satisfaction with other subscales was the same for both males and females. Similarly, AlDossary et al. ${ }^{[21]}$ found no significant relationship between gender and job satisfaction. This is perhaps because the males were only $11.3 \%$ of the population, there may not have been sufficient gender diversity to detect the differences. The higher satisfaction with autonomy of practice and professional role enactment among the male nurses could be because most of the time the male nurses are in management positions and that is why they were more satisfied with being in control of their work and more sense of achievement since administrative positions are associated with motivation itself and to satisfaction. ${ }^{[2]}$ It was established that male nurses earned more, felt they had better job security and got better employment opportunities in nursing. ${ }^{[14]}$ More male nurses felt they had a workplace support network.

\subsection{Comparison between age, work experience and job satisfaction}

The older nurses and those who had worked longer experienced more satisfaction with almost all the subscales. These findings are consistent with those of Li et al. and Wang et al. ${ }^{[2,25]}$ who confirmed that years of experience is positively correlated with job satisfaction. Older nurses with more years of experience are more satisfied with their jobs. ${ }^{[23]}$ Individual characteristics do not determine job satisfaction for nurses at all. ${ }^{[26]}$ It is expected that as nurses age in their career, they are able to make independent decisions, relate well with co-workers especially the physicians, gain expertise in their work and hold higher/managerial positions in their units. Promotions and fringe benefits are frequently based on one's age and amount of experience thus the older nurses might have access to these benefits and therefore perceive their jobs more positively. It is possible that the older nurses have settled in their careers and are now focusing their energies on improving the career and serving the communities.

The perception of job satisfaction is being influenced by generational differences among the nurses. ${ }^{[24,27,28]}$ The nursing workforce in this study comprised of three generations, baby boomers (1946-1964), generation Xers (1965-1979) and Nexters (Generation Y) (1980-2000). This classification was done in the USA but Mucheru ${ }^{[29]}$ used the same to describe the Kenyan work force. The sample in the current study also fit in this classification. The generation Xers and Nexters want less bureaucracy and more autonomy. They want to be part of every decision that is made. The structure of the Kenyan public hospitals is that decisions are made from the central government; these young nurses may feel they are not participating adequately in decision and policy making thus feeling dissatisfied with their job. All the nurses regardless of age were relatively dissatisfied with their benefits (see Table 8), contradicting the findings of Gaki ${ }^{[22]}$ who suggested that remuneration especially concerned older nurses. The satisfaction with benefits in this study also did not significantly differ with job experience whereas Li et al. ${ }^{[2]}$ found that there is more satisfaction when one has a longer work experience.

\subsection{Comparison between professional qualification and job satisfaction}

The certificate holders who have less academic qualifications than the diploma and the degree holders were more satisfied with their jobs. Nurses who are older, have more years of nursing experience and more years of experience in the current unit are more likely to have a lower level of nursing education. This would be expected because until the 1990s nurses in Kenya were not being trained at the degree level. When the program was introduced, it was not clear what the roles of the graduate nurses would be and therefore many young people did not embrace it. Nevertheless, Gurkova et al. and Wang et al. ${ }^{[25,26]}$ found that educational level was not significantly related to job satisfaction. It appears the studies that are conducted in specialty areas like critical care and obstetric units have job satisfaction influenced by ed- 
ucational level unlike other general areas where education level has minimal impact on job satisfaction. One can argue that nurses in specialty areas need specific training which is conducted at only certain educational level whereas for the general areas, basic training may be adequate to provide the required patient care.

\subsection{Correlation between the main subscales}

The subscales positively correlated with one another, that is the motivation factors positively correlated with the hygiene factors. This means if nurses were satisfied with one subscale, they were likely to be satisfied with all the others and vice versa. A combination of factors contribute to job satisfaction. ${ }^{[23]}$ Further, job satisfaction generally acts like a pendulum in which the "self" is the central axis and the "self" can stabilize satisfaction and direct the effect on other variables on staff satisfaction. ${ }^{[30]}$ They further assert that the job satisfaction phenomenon rounds out the individual's self and so it is the nurses themselves that should strive, plan, keep and promote job satisfaction.

\section{Conclusion}

The nursing workforce in the obstetric units comprises of mostly females, who are above 36 years, have been in nursing for more than 20 years but have been in the obstetric units for fewer years. This study points out that nurses are still more interested in service work and developing themselves professionally by having clinical challenges and having adequate in-service opportunities. Nurses are displeased when they are not able to complete direct patient care tasks and they do not receive adequate remuneration that corresponds to how much they are giving to the patients and the institutions in which they work. The nurses working in the obstetric units are relatively more satisfied with professional role enactment and work worth to self and others than professional work environment, autonomy of practice, professional relationships and benefits. They are more satisfied with the motivation factors than with the hygiene factors.Similar to many other studies, there were no significant differences in job satisfaction between the male and the female nurses. The study also reveals that all aspects of the job are essential for job satisfaction to be realized. The aspects are interrelated and a reduction in one aspect directly is correlated with a reduction in the other.

\subsection{Limitations}

This research has generated some significant findings but there are some limitations that need to be acknowledged. First, the sample size was quite small as compared to the whole nursing workforce and the participants were picked from only two public hospitals using convenience sampling method. Generalization of these findings to other lower level and higher level hospitals as well as private hospitals is therefore limited. Secondly, the work quality index (WQI) questionnaire had scores ranging from 1 to 7 with 1 representing not satisfied and 7 representing satisfied. The middle scores were not explicit on the level of satisfaction or dissatisfaction and thus may have been ambiguous for the participants to complete and in such a case many participants may have tended to tick the middle score. Thirdly, the unavailability of published research from Kenya and generally Africa made it difficult to compare the current findings with those from the western countries since their applicability to Kenya is not certain.

\subsection{Implications for practice}

The findings of this research add to a body of knowledge that exists mainly from western countries about factors that influence nurses' job satisfaction. The nurse midwives have shown less satisfaction with many factors of the job, both the motivation and the hygiene factors. There is therefore need to focus on ways that increase the satisfaction and this requires collaboration between nurse managers and the policy maker which is the government of Kenya. The work conditions should be refurbished to ensure it meets the requirements of a professional work environment. Borrowing from the magnet characteristics of the USA hospitals seems would help create job satisfaction for nurse midwives which in turn would ensure quality nursing care for patients and retention of professional nurses. Such changes require immense financial support and therefore the ministry of finance need to relook at the annual allocation to the ministry of health as it seems traditionally it has not adequately provided for the ministry of health.

\subsection{Implications for further research}

Little seems to have been done to explore the impact of the degree in nursing to health care provision since its inception in the 1990s. A study to explore the perceptions of those who have undergone this training would help unravel the reasons behind high turnover and high attrition rates both during training and while working. The poor relationship between nurse midwives and physicians need to be investigated further so as to enhance communication and collaboration between the two teams. Future research should consider a larger sample possibly a national sample to include nurse midwives from all levels of health care provision and those from the private sector.

\section{CONFlicts OF InTEREST Disclosure}

The author declares that there is no conflict of interest. 


\section{REFERENCES}

[1] Choi S, Cheung K, Pang S. Attributes of nursing work environment as predictors of registered nurses job satisfaction and intention to leave. Journal of Nursing Management. 2012; 1-11 p.

[2] Li J, Lambert V. Job satisfaction among intensive care nurses from People's Republic of China. International Nursing Review. 2008; 55(1): 34-39. PMid:18275533 https : //doi .org/10.1111/j.14 66-7657.2007.00573.x

[3] Bogaert P, Clarke S, Roelant E, et al. Impact of unit-level nurse practice environment and burnout on nurse-reported outcomes: a multilevel modeling approach. Journal of Clinical Nursing. 2009; 19: 1664-1674. PMid:20579204 https://doi.org/10.1111/j . 1365-2702.2009.03128.x

[4] Herzberg F, Mausner B, Synderman B. The motivation to work. John Wiley and Sons; 1953.

[5] Lobiondo-Wood G, Haber J. Nursing Research: methods and critical appraisal for evidence-based practice. sixth edition, Mosby; 2006.

[6] Polit D, Beck C. Nursing research: Appraising evidence for nursing practice, Seventh edition. Philadelphia, Lippincott: 2010.

[7] Muller-Staub M, et al. Improved quality of nursing documentation: results of a nursing diagnoses, interventions and outcomes implementation study. Journal of Nursing Terminologies and Classifications. 2007; 18(1 Jan-March): 5-17.

[8] Polit D, Beck C. Nursing research: generating and assessing evidence for nursing practice, ninth edition. Philadelphia, Lippincott: 2012.

[9] Ministry of Health. Focused antenatal care: Orientation package for service providers. 4th Edition. 2009.

[10] Ministry of Health. Organization of health services in Kenya. 2009.

[11] Whitley M, Putzier D. Measuring nurses satisfaction with the quality of their work and work environment. Journal of Nursing Care Quality. 1994; 8(3): 43-51. PMid:8018972 https://doi.org/10.1097/ 00001786-199404000-00008

[12] Kenya's Health Workforce. Training Capacity: A Situation Analysis. 2010.

[13] Rajacich D, Kane D, Williston C, et al. If they do call you a nurse, it is always a 'male nurse': experiences of men in the nursing profession. Nursing Forum. 2013; 48(1): 71-80. PMid:23379398 https://doi.org/10.1111/nuf . 12008

[14] Andrews M, Stewart N, Morgan D, et al. More alike than different: a comparison of male and female RNs in rural and remote Canada. Journal of Nursing Management. 2012; 20: 561-570. PMid:22591157 https://doi.org/10.1111/j.1365-2834.2011.01195.x

[15] Nursing Council of Kenya. Kenya Registered Nurse Program. Students training Material file. 2009.

[16] Gross J, Rogers M, Teplinskiy I, et al. The impact of out-migration on the nursing workforce in Kenya. 2011; 1-24 p.

[17] Doef M, Mbaazi F, Verhoeven C. Job conditions, job satisfaction, somatic complains and burnout among East African nurses. Jour- nal of Clinical Nursing. 2012; 21: 1763-1775. PMid:22458703 https://doi.org/10.1111/j.1365-2702.2011.03995.x

[18] Nursing Council of Kenya. Scope of practice for nurses in Kenya. 3rd edition. 2012.

[19] Nursing Council of Kenya. Standards of nursing education and practice for nurses in Kenya. 2nd edition. 2012.

[20] Hagopian A, Zuyderduin A, Kyobutungi N, et al. Job satisfaction and morale in the Ugandan health workforce. Health Affairs. 2009; 28: 863-875. PMid:19661112 https : //doi.org/10.1377/hlthaff . 28. 5. w863

[21] Al-Dossary R, Vail J, Macfarlane F. Job satisfaction of nurses in a Saudi Arabian university teaching hospital: a cross-sectional study. 2012.

[22] Gaki E, Kontodimopoulos N, Niakas D. Investigating demographic, work-related and job satisfaction variables as predictors of motivation in Greek nurses. Journal of Nursing Management. 2012; 1-8 p.

[23] Hayes B, Bonner A, Pryor J. Factors contributing to nurse job satisfaction in the acute hospital setting: A review of recent literature. Journal of Nursing Management. 2010; 18: 804-814. PMid:20946216 https://doi.org/10.1111/j.1365-2834.2010.01131.x

[24] Zangaro G, Johantgen M. Registered nurses job satisfaction in navy hospitals. Military Medicine. 2009; 174(1): 76-81. PMid:19216301 https ://doi.org/10.7205/MILMED-D-04-1307

[25] Wang L, Tao H, Ellenbecker C, et al. Job satisfaction, occupational commitment and intent to stay among Chinese nurses: a crosssectional questionnaire survey. Journal of Advanced Nursing. 2011; 68(3): 539-549. PMid:21722170 https://doi.org/10.1111/j . 1365-2648.2011.05755.x

[26] Gurkova E, Ziakova K, Duriskova M. Job satisfaction and emotional subjective well-being among Slovak nurses. International Nursing Review. 2012; 59: 94-100. https ://doi.org/10.1111/j.1466 $-7657.2011 .00922 . \mathrm{x}$

[27] Sparks A. Psychological empowerment and job satisfaction between baby boomers and generation x nurses. Journal of Nursing Management. 2012; 20: 451-460. PMid:22591147 https ://doi .org/10 $.1111 / \mathrm{j} .1365-2834.2011 .01282 . \mathrm{x}$

[28] Wilson B, Squires M, Widger K, et al. Job satisfaction among a multigenerational nursing workforce. Journal of Nursing Management. 2008; 16: 716-723. PMid:18808466 https ://doi.org/10.1111/ j.1365-2834.2008.00874.x

[29] Mucheru J. Debunking generation 'Y'. Management, July 2012; 17-19 p.

[30] Ravari A, Bazargan M, Vanaki Z, et al. Job satisfaction among Iranian hospital-based practicing nurses: examining the influence of self-expectation, social interaction and organizational situations. Journal of Nursing Management. 2012; 20: 522-533. PMid:22591154 https ://doi.org/10.1111/j.1365-2834.2010.01188.x 